\title{
ASPECTOS CONTROVERSOS SOBRE A (IN) APLICABILIDADE DO REGIME FALIMENTAR ÀS COOPERATIVAS DE CRÉDITO.
}

Flávio Couto Bernardes ${ }^{1}$

Suélen Marine Silva ${ }^{2}$

\section{Resumo:}

O presente trabalho versa sobre a aplicabilidade do regime falimentar às cooperativas de crédito. O problema é destacado a partir da análise do artigo $1^{\circ}$ da Lei n. 6.024 de 1974 e os artigos $2^{\circ}$, II e 197 da Lei 197 da Lei n. 11.101 de 2005. Ao final conclui-se que a tese apresentada é a adequada por demonstrar que há aplicabilidade do regime falimentar às cooperativas de crédito após a liquidação pelo Banco Central diante do permissivo legal da Lei n. 6024 de 1974. A metodologia utilizada foi a descritiva e qualitativa com estudo da doutrina, jurisprudência e legislação.

Palavras Chave: Cooperativismo. Instituições financeiras. Equiparação. Cooperativas de crédito. Falência.

\section{Controversial aspects about the (in) applicability of the bankruptcy to credit cooperatives.}

\begin{abstract}
This paper deals with the applicability of the bankruptcy regime to credit unions. The problem is highlighted from the analysis of article 1 of Law no. 6,024 of 1974 and Articles 2, II and 197 of Law 197 of Law no. 11.101 of 2005 . In the end it is concluded that the thesis presented is adequate because it demonstrates that the bankruptcy regime is applicable to credit unions after liquidation by the Central Bank before the legal permissive of Law no. 6024 from 1974. The methodology used was descriptive and qualitative with study of doctrine, jurisprudence and legislation.
\end{abstract}

Keywords: Cooperativism. Financial Institution. Matching. Credit unions. Bankruptcy.

\section{Introdução}

\footnotetext{
${ }^{1}$ Doutor (2006), Mestre (2000) e Bacharel (1994) em Direito pela Universidade Federal de Minas Gerais. Membro do corpo docente do Programa de Pós-Graduação em Direito da Pontifícia Universidade Católica de Minas Gerais. Professor de Direito Tributário e Financeiro da UFMG. Procurador do Município de Belo Horizonte. Secretário da Associação Brasileira de Direito Tributário - Abradt. Advogado.

E-mail: flavio.bernardes@ bernardesadvogados.adv.br

${ }^{2}$ Advogada. Mestranda em Direito Público pela Pontifícia Universidade Católica de Minas Gerais. Especialista em Direito de Empresa e Direito Processual pelo Instituto de Educação Continuada da PUC Minas. Bacharel em Direito pela Pontifícia Universidade Católica de Minas Gerais. Endereço Eletrônico: suelen_marine@yahoo.com.br
} 
O direito do cooperativismo ${ }^{3}$ permanece sendo tratado na legislação brasileira pela Lei n. 5.764, de 1971. No entanto, em 2002, com a promulgação do Código Civil, o legislador conferiu às cooperativas um capítulo no livro das empresas intitulado sociedades cooperativas, atribuindo às mesmas, no que a lei especial for omissa, a aplicação das regras da sociedade simples previstas nos artigos 1.096 e seguintes.

Considerando que o cooperativismo está dividido em ramos ou setores econômicos aplicáveis, o interesse do presente trabalho volta-se ao intitulado cooperativismo de crédito, equiparado juridicamente por determinadas normas jurídicas ${ }^{4}$ às instituições financeiras. Essa área negocial vem mostrando amplo crescimento nos últimos anos, sendo o terceiro tipo cooperativo mais procurado.

Diante desse crescimento, surge a necessidade de saber como proceder em caso de crise econômica nas cooperativas de crédito e qual modalidade de intervenção aplicar. Seguindo as regras da Lei n. 6.024/1974, aplicam-se às instituições financeiras e às cooperativas de crédito a intervenção e a liquidação extrajudicial por parte do Banco Central. Mais tarde, o Decreto-Lei n. 2.321/1987 institui o RAET - Regime de Administração Especial Temporária, também decretado pelo Banco Central.

Ocorre que a grande controvérsia veio com o advento da Lei n. 11.101/2005, conhecida como a norma da recuperação judicial, extrajudicial e falências, que no artigo $2^{\mathrm{a}}$, inciso II, veda sua aplicação às instituições financeiras e às cooperativas de crédito, mas faz uma ressalva no artigo 197, estabelecendo que pode aplicar o instituto jurídico da falência às referidas pessoas jurídicas quando a lei especial que as rege for omissa sobre o tema.

Nesse contexto, o presente trabalho apresenta a síntese da história do cooperativismo no Brasil, especialmente no setor de crédito, buscando examinar qual legislação deve ser aplicada no caso de crise, ou seja, se pode ser utilizado o regramento previsto na Lei n. 11.101/2005. Para tanto, foram analisadas a doutrina jurídica, jurisprudência, legislação e análise de dados dos números das cooperativas de crédito no Brasil, adotando-se a metodologia descritiva e qualitativa.

\section{O cooperativismo e sua regulamentação no Brasil.}

\footnotetext{
${ }^{3}$ Waldírio Bulgarelli defende a autonomia do Direito Cooperativo por possuir legislação e princípios próprios.

${ }^{4} \mathrm{O}$ artigo $1^{\circ}$ da Lei n. 6024 de 1974 equipara as cooperativas de crédito às instituições financeiras e o artigo 192 da Constituição Federal integra as cooperativas de crédito ao sistema financeiro nacional.
} 
Desde os tempos mais remotos o homem unia-se uns aos outros para conseguir sobreviver, de onde basicamente remonta a ideia do espírito cooperativista. Na leitura dos textos bíblicos percebe-se o cooperativismo existente naquela época. Nesse sentido, Nilson Reis Júnior afirma que Jesus Cristo e seus apóstolos praticavam o cooperativismo como ideologia de vida, pregando o bem comum acima de qualquer outro valor. No mesmo sentido elucida que:

\begin{abstract}
“As raízes do cooperativismo são encontradas na mais remota antiguidade. Entre os babilônios, já havia o arrendamento de terras para a exploração comum. Entre os gregos e romanos, havia sociedades de auxílio mútuo para os enterros e seguros. No Egito, resultava, quase sempre, no cumprimento de dever criado pelo poder público. Os próprios monastérios e corporações medievais podem ser considerados formas embrionárias de cooperativas". (REIS JÚNIOR, 2006, p. 25)
\end{abstract}

As corporações de ofício da idade média, surgidas a partir do século XII, também podem ser consideradas cooperativas, pois nelas havia a fabricação artesanal dos bens e as pessoas se uniam para defender seus interesses, bem como para conseguir negociar seus produtos de forma mais ampla. Essas corporações foram extintas com a eclosão da Revolução Industrial, ocorrida na Inglaterra em meados do século XVIII.

Com a Revolução Industrial, o meio de produção e a economia mudaram, pois a força de trabalho passou a ser mecanizada e a competitividade aumentou. Entretanto, a péssima condição de trabalho e a falta de direitos trabalhistas fizeram com que a classe trabalhadora começasse a se revoltar, eclodindo protestos como o ludismo ${ }^{5}$ e o cartismo ${ }^{6}$.

Foi nesse contexto que o cooperativismo toma os contornos na modalidade como atualmente é conhecido. No bairro de Rochdale em Manchester, Inglaterra, 27 tecelões e uma tecelã se uniram para formar a Sociedade dos Probos de Rochdale, conhecida como a primeira cooperativa moderna do mundo, que tinha por objetivos abrir lojas, construir casas para seus sócios e fábricas para dar trabalho aos desempregados (CARNEIRO, 1981.p. 33).

Atribui-se aos pioneiros de Rochdale a criação dos princípios do cooperativismo vigentes até hoje. Os princípios criados pelos referidos membros e que disciplinam o regime cooperativo são: adesão livre e voluntária; controle democrático pelos sócios; participação econômica dos sócios; autonomia e independência; educação, treinamento e informação; e cooperação entre as cooperativas. Mais tarde, em 1995 a Aliança Internacional Cooperativa estudou novamente os princípios e acrescentou o princípio da preocupação com a comunidade.

\footnotetext{
${ }^{5}$ Ludismo foi um movimento de trabalhadores ingleses do ramo de fiação e tecelagem, ativo no início do século XIX, nos primórdios da Revolução Industrial, e que se notabilizou pela destruição de máquinas como forma de protesto.

${ }^{6}$ Cartismo foi um movimento político de cunho reformista, que ocorreu na Inglaterra entre 1837 e 1848 Dele resultou a Carta do Povo, redigida em 1838, que continha o programa do movimento.
} 
Desde seu surgimento o movimento cooperativista possui como classificação três fases históricas, de acordo com VERÇOSA (2010, p. 566): fase primitiva, que vai até 1895; a segunda fase intitulada de desenvolvimento, que vai de 1895 até 1914; e a terceira fase chamada de consolidação, que vai de 1914 até os dias atuais.

O cooperativismo nasceu em resposta ao capitalismo e mais tarde se opôs ao socialismo. Diante dos ideais dos pioneiros de Rochdale, as cooperativas foram se espalhando pelo mundo, sendo que em 1863 já havia 88 cooperativas coordenadas como o registro de “Cooperative Wholesale Society”, que passou a ter atividades variadas como saúde, educação, crédito, entre outras. (CARNEIRO, 1981, p. 34)

No Brasil, desde a época colonial a cultura da cooperação foi cultivada, mas somente no fim do século XIX que o movimento cooperativista tomou forma com os militares, funcionários públicos e profissionais liberais que se uniam para atender às suas necessidades. Nilson Reis Júnior (2006, p. 32) aduz que "os primórdios do movimento cooperativista no Brasil data de 1847, com a fundação, nos sertões do Paraná, pelo médico Francês Jean Maurice Faivre, da colônia "Tereza Cristina", que restou organizada em princípios cooperativistas".

De acordo com a Organização das Cooperativas do Brasil - OCB, a primeira cooperativa de que se tem notícia no território pátrio foi fundada em Ouro Preto, Minas Gerais, em 1899, denominada Sociedade Cooperativa Econômica dos Funcionários de Ouro Preto. Tratava-se de uma sociedade de consumo, tendo sido o passo inicial para o surgimento de outras cooperativas nos demais Estados-membros da federação.

A partir desse marco o cooperativismo passou a ser previsto na Constituição de $1891^{7}$, sendo que partir dessa inserção constitucional foram editadas diversas normas para regulamentar as cooperativas. A título de exemplo, o Decreto n. 979, de 1903, foi promulgado pelo governo de Rodrigo Alves, facultando aos agricultores e industriais rurais a formação de caixa de crédito agrícola e de cooperativas de produção e consumo. O Decreto n. 1.637/1907, por sua vez, enumerou as características das cooperativas, mas não atribuiu a elas forma própria.

Em 1932 foi promulgado o Decreto n. 22.239, que sob inspiração rochdaleana constituiu marco jurídico para as cooperativas. Este diploma normativo previa que as cooperativas eram sociedades de pessoas e não de capitais, com forma sui generis, que se distinguia das demais. Em 1966 foi promulgado o Decreto-Lei n. 59, que regulamentado pelo

\footnotetext{
${ }^{7}$ Art. 72 - A Constituição assegura a brasileiros e a estrangeiros residentes no país a inviolabilidade dos direitos concernentes a liberdade, a segurança individual e a propriedade, nos termos seguintes: (...) $\S 8^{\circ}$ - A todos é lícito associarem-se e reunirem-se livremente e sem armas, não podendo intervir a polícia senão para manter a ordem pública.
} 
Decreto n. 60.597 de 1967, disciplinou a institucionalização das sociedades cooperativas e criou o Conselho Nacional do Cooperativismo.

Em 1969 foi criada a Organização das Cooperativas Brasileiras - OCB - que nasceu como o objetivo de defender os interesses do cooperativismo brasileiro. Apenas em 1971 foi editada a Lei n. 5.764/71, marco legal do cooperativismo, a qual disciplina a criação de cooperativas, embora com forte intervenção estatal frente aos associados. Essa situação apenas foi alterada com a promulgação da Constituição de 1988.

Exatamente o artigo 5a , inciso XVIII, do Texto Maior, que Waldirio Bulgarelli (2000, p. 05) considera o dispositivo mais importante, dispondo: "a criação de associações e, na forma da lei, a de cooperativas, independem de autorização, sendo vedada a interferência estatal em seu funcionamento". Destacam-se, ainda, outros dispositivos da Constituição Federal que versam sobre as cooperativas, dentre eles os artigos 146, alínea “c” e 174, $\S \S 2^{\mathrm{a}}$ e $3^{\mathrm{a}}$.

Com a promulgação do Código Civil, em 2002, foi incluído no livro das empresas o título dedicado às sociedades cooperativas, regulando as disposições gerais relativas às entidades em comento, aplicando-se a elas, caso não existindo disposição em lei específica, as regras da sociedade simples.

De acordo com a Organização das Cooperativas de Minas Gerais - OCEMG - em 2014 o Brasil possuía 7.237 cooperativas, distribuídas em todos os Estados, com maior concentração nas regiões sul e sudeste do país. Minas Gerais representa 10,6\% desse número, com 781 cooperativas registradas no Sistema OCEMG. Com uma participação anual de 6,4\% no PIB mineiro, o setor, que agrega 925.701 cooperados e 29.829 empregados, é responsável por uma movimentação anual de R $\$ 18,4$ bilhões $^{8}$.

\subsection{A natureza jurídica das cooperativas.}

A Lei n. 5.764/71, ao conceituar as cooperativas, conferiu às mesmas uma natureza jurídica específica, ainda que civil. $\mathrm{O}$ artigo $4^{\circ}$ da referida lei conceitua as cooperativas da seguinte forma:

“Art. $4^{\circ}$ - As cooperativas são sociedades de pessoas, com forma e natureza jurídica próprias, de natureza civil, não sujeitas à falência, constituídas para prestar serviços

\footnotetext{
${ }^{8}$ Informação disponível in: < ORGANIZAÇÃO DAS COOPERATIVAS DO ESTADO DE MINAS GERAIS. Anuário de informações econômicas e sociais do cooperativismo mineiro. Disponível em: <http://www.minasgerais.coop.br/Repositorio/Publicacoes/anuario_2013/index.html\#/10/>. Acesso em: 20. ago. 2019>.
} 
aos associados, distinguindo-se das demais sociedades pelas seguintes características:” (BRASIL, 1971).

Não se trata de definição que exala clareza e objetividade, sendo que ao abordar a matéria Nilson Reis Júnior (2006, p.52) assevera:

\begin{abstract}
"Na realidade, essa conceituação proporcionou uma enorme confusão. Isso porque restou inserido no referido artigo às expressões: a) com forma e natureza jurídica próprias; e b) de natureza civil, de modo que a cooperativa passou a ser a única sociedade no direito brasileiro com duas naturezas diferentes" (REIS JÚNIOR, 2006, p.52).
\end{abstract}

Ao fazer a confusão sobre sua exata natureza jurídica, já que específica em relação às entidades de natureza civil, o legislador de 1971 abriu imenso debate doutrinário acerca desse instituto e seu consequente regime jurídico. Desde seu surgimento na legislação brasileira não houve um consenso para definir qual a dimensão de sua natureza jurídica e as peculiaridades daí decorrentes. Sobre o tema Nilson Reis Junior (2006, p. 50) mostra que: "Ao longo do desenvolvimento da legislação cooperativista no País, a natureza
jurídica dessa sociedade já foi considerada de diversas maneiras: ora sociedade sui
generis, ora civil (hoje simples), ora comercial (hoje empresária), por possuir modelo
próprio, e hoje, de sociedade simples. Acreditamos, contudo, que tal fato deve-se à
forma imprecisa e controvertida com que foi tratada pela lei” (REIS JÚNIOR, 2006,
p. 50).

Analisando o artigo 966 do Código Civil de 2002, este estabelece: "Considera-se empresário quem exerce profissionalmente atividade econômica organizada para a produção ou a circulação de bens ou de serviços". A cooperativa, apesar de não ter fins lucrativos, assemelha-se a uma sociedade empresária ${ }^{9}$, ainda que classificada como sociedade simples pelo Código Civil, visto que de acordo com o artigo supracitado exerce atividade econômica organizada para a produção ou circulação de bens ou serviços. Mesmo sendo uma sociedade que visa atividade econômica, na sua constituição dispensa o capital e prioriza a pessoa, sendo tratada pelo Código Civil justamente como Sociedade Simples no parágrafo único artigo 982.

Diante da dúvida acerca de sua natureza jurídica, o posicionamento defendido por Haroldo Malheiros Duclerc Verçosa (2010, p. 568) sustenta a tese de ter as cooperativas natureza jurídica hibrida. Sustenta o doutrinador:

"Desta maneira, as cooperativas ficam a meio caminho entre as sociedades civil e as
sociedades empresárias, cabendo-lhes a natureza jurídica de ente hibrido, ou
sociedade sui generis, conforme tem sido discutido na doutrina" (VERÇOSA, 2010,
p.568).

O Código Civil de 2002 prevê um capitulo para as cooperativas, não as definindo, mas conferindo ás mesmas a natureza jurídica de uma sociedade simples, o que foi um retrocesso por parte do legislador ao não definir às cooperativas um regime jurídico próprio, mesmo sendo de natureza civil, por se tratar de um híbrido entre os modelos existentes.

\footnotetext{
9 Há divergência doutrinária quanto à natureza jurídica das cooperativas. O Código Civil de 2002 classificou as cooperativas como sociedade simples, entretanto autores como: Waldírio Bulgarelli, na obra "As sociedades cooperativas e a sua disciplina jurídica", 2 ed.; e Nilson Reis Júnior, na obra "Aspectos Societários das Cooperativas"; quando ambos afirmam sua natureza sui generis.
} 
Os projetos de lei sobre o cooperativismo, que foram arquivados, como o PL n. 171/99 de autoria do senador Osmar Dias, o PL n. 428/99, de autoria do ex-senador José Fogaça, e o PL n. 605/99, de autoria do ex-senador Eduardo Suplicy, visavam a substituição da Lei n. 5764/71, sendo que todos esses projetos atribuíam regime jurídico próprio à cooperativa.

\subsection{As cooperativas de crédito.}

As cooperativas de crédito foram criadas na Europa na segunda metade do século XIX, na Alemanha e Itália. Em 1847, um juiz chamado Friedrich Raiffeisen criou no Estado alemão da Baviera a primeira associação cooperativa para a comunidade rural. Essa associação não era uma cooperativa propriamente dita, mas viria a ser o modelo da cooperativa Raiffeisen. A ideia dessas cooperativas de créditos rurais era que as pessoas pudessem juntar dinheiro e tomar empréstimos mutuamente, objetivando o desenvolvimento econômico de suas atividades.

Em 1856 foi a vez de o prussiano Herman Schulze criar as cooperativas urbanas. Foi a primeira associação de dinheiro antecipado com a previsão de retorno das sobras líquidas de acordo com o capital disponibilizado individualmente pelos cooperados.

O italiano Luigi Luzzatti, inspirado nos alemães, criou em 1865 em Milão o modelo de cooperativa que não exigia vínculo para a associação, não remuneração dos dirigentes, responsabilidade limitada ao valor subscrito e quotas de capital de pequeno valor. Esse modelo de cooperativa que leva o nome de Luzzatti inspirou a criação de cooperativas de crédito no Brasil.

Na America do Norte, Alphonse Desjardins criou no Canadá, em 1900, uma cooperativa inspirada nos modelos de Raiffeisen, Schultze - Delitzsch e Luzzatti. Esse tipo de cooperativa é conhecido hoje no Brasil como cooperativa de crédito mútuo, tendo como principal característica a existência de alguma espécie de vínculo entre os sócios, reunindo grupos homogêneos como os de clubes, trabalhadores de uma mesma fábrica, funcionários públicos ou outros grupos integrados por um interesse comum no exercício da atividade.

No Brasil, a primeira cooperativa de crédito foi fundada em Nova Petrópolis, Rio Grande do Sul, em 1902, pelo Padre Jesuíta Theodor Amstadt. Essa cooperativa de crédito foi inspirada no modelo Raiffeisen, pois era vinculada a fundo rural. Está ativa nos dias de hoje, sendo conhecida como Sicredi (PINHERO, 2008, p. 23).

Nessa cooperativa era admitida qualquer pessoa e se aplicava preferencialmente a pequenas comunidades rurais ou vilas. Baseava-se nos princípios Rochdaleanos, visto que dava mais importância à pessoa do que ao capital. Foi muito bem sucedida no Rio Grande do Sul, 
chegando a dispor de uma cooperativa central com mais 50 cooperativas singulares a ela filiadas.

Mais tarde, no final da década de 20, chega ao Brasil a cooperativa de crédito do modelo Luzzatti, trazido pelos leigos da igreja católica que foram para Roma participar de um congresso mariano, onde conheceram o citado modelo, trazendo e o implantando por aqui. Se diferenciava do modelo alemão no sentido de que seu público alvo eram os pequenos empresários, artesãos, assalariados comerciantes ou industriais. Essa cooperativa denominada Caixa Econômica de Empréstimo de Lajeado foi fundada na cidade de Lajeado, Rio Grande do Sul, e continua em atividade até hoje sob o nome de Cooperativa de Crédito de Lajeado (PINHEIRO, 2008, 26).

No final da década de 50 foi a vez do modelo desenvolvido pelo canadense Alphonse Desjardins, tendo sido implantado no Rio de Janeiro por Maria Thereza Rosália Teixeira Mendes com o apoio do bispo auxiliar Dom Hélder Câmara.

Durante a ditadura militar foi implantado diversas exigências para a implantação e funcionamento das cooperativas de crédito, sendo que muitas acabaram ficando na clandestinidade. Sobre tal fato assevera PINHO (1999, p. 14):

\footnotetext{
"Nos anos 60, durante o regime militar, foi realizada uma reforma no sistema financeiro brasileiro, estabelecendo diversas exigências para o funcionamento das cooperativas de crédito. Estas exigências acabaram por "liquidar" um grande número de cooperativas, obrigando outras a se reestruturarem e limitarem sua atuação. Nos anos 70 e início dos anos 80, o cooperativismo de crédito no Brasil restringiu-se a praticamente dois campos: às cooperativas de crédito mútuo, fechadas aos empregados de grandes empresas, e às de crédito rural, vinculadas às cooperativas de produção. Das 65 Cooperativas de Credito que existiam no Rio Grande do Sul em 1964, sobraram apenas treze no final dos anos 70" (PINHO, 1999, p. 14).
}

A partir da década de 80 o movimento das cooperativas de crédito começou a reagir e surgiram os primeiros bancos cooperativistas do Brasil: o Bancoob e o Bansicredi. Ainda na mesma época o número das cooperativas de crédito aumentou e se espalhou por todo território nacional.

Após a promulgação da Constituição Federal de 1988 que a situação das cooperativas de crédito melhorou, já que não mais permite a intervenção estatal na sua criação e funcionamento.

O cooperativismo de crédito tem cinco grandes blocos: três são os Sistemas Sicredi, Sicoob, Unicred, e os outros dois blocos são as cooperativas de crédito independentes e as cooperativas econômica e solidária. 


\title{
3. Equiparação das cooperativas de crédito às instituições financeiras.
}

Tema de grande relevância para o presente trabalho é a questão da equiparação das cooperativas de crédito com as instituições financeiras. A definição de instituição financeira é dada pelo artigo 17 da Lei n. 4.595/1964, que dispõe:

Art. 17 - Consideram-se instituições financeiras, para os efeitos da legislação em vigor, as pessoas jurídicas públicas ou privadas, que tenham como atividade principal ou acessória a coleta, intermediação ou aplicação de recursos financeiros próprios ou de terceiros, em moeda nacional ou estrangeira, e a custódia de valor de propriedade de terceiros. (BRASIL, 1964)

De posse da definição de instituição financeira, importante destacar que banco e cooperativas de crédito não são a mesma coisa. Em termos históricos os bancos existem desde a antiguidade clássica grega e romana e as cooperativas de credito sugiram a partir da revolução industrial. SENRA (2005, p. 331) mostra que:

\begin{abstract}
O banco tem origem na Antiguidade, surgiu como consequência do desenvolvimento do capitalismo. Trata-se de verdadeiro aprimoramento da atividade comercial exercida pelos mercadores. Já a sociedade cooperativa (não apenas a de crédito) ou a pratica da doutrina cooperativista tem origem na época moderna, no seio da expansão do capitalismo, tendo surgiu como meio de acumulação e economia de capital (comum) para os empregados das manufaturas ou industrias que era explorados pelos industriais da época e se encontravam em uma situação de penúria, exploração e descapitalização. Não restam duvidas de que a cooperativa é exemplo verdadeiro de sociedade comunitária, visando o bem comum dos associados. (SENRA, p. 331)
\end{abstract}

Até mesmo na definição e na sua finalidade o banco se difere da cooperativa de crédito, pois enquanto o primeiro busca o lucro, estas visam a ajuda mútua sem fins lucrativos. Banco é um estabelecimento mercantil de crédito, sob forma de sociedade anônima, que tem por objeto o comércio de dinheiro ou de títulos representativos de valores; já a cooperativa de crédito é uma sociedade de pessoas, possuindo personalidade jurídica própria e classificadas pelo Código Civil de 2002 como sociedades simples, não se sujeitando como regra à falência. Todavia, insta ressaltar que as cooperativas de crédito são equiparadas para diversos fins de controle às instituições financeiras, como prevê a Lei n. 6.024/1974.

$\mathrm{Na}$ legislação pátria, bancos e cooperativas de créditos sempre foram regulados por normas próprias. Apenas em 1964, com o advento da Lei n. 4.595, que houve a equiparação das cooperativas de crédito às instituições financeiras com o intuito de regulamentação do setor 
de crédito, embora possuam regimes jurídicos distintos, como destacado anteriormente. $\mathrm{O}$ artigo $18, \S 1^{\circ}$, da Lei n. 4.595/1964, disciplina que:

\begin{abstract}
Art. 18 - As instituições financeiras somente poderão funcionar no País mediante prévia autorização do Banco Central da República do Brasil ou decreto do Poder Executivo, quando forem estrangeiras.

$\S 1^{\circ}$ - Além dos estabelecimentos bancários oficiais ou privados, das sociedades de crédito, financiamento e investimentos, das caixas econômicas e das cooperativas de crédito ou a seção de crédito das cooperativas que a tenham, também se subordinam às disposições e disciplina desta lei no que for aplicável, as bolsas de valores, companhias de seguros e de capitalização, as sociedades que efetuam distribuição de prêmios em imóveis, mercadorias ou dinheiro, mediante sorteio de títulos de sua emissão ou por qualquer forma, e as pessoas físicas ou jurídicas que exerçam, por conta própria ou de terceiros, atividade relacionada com a compra e venda de ações e outros quaisquer títulos, realizando nos mercados financeiros e de capitais operações ou serviços de natureza dos executados pelas instituições financeiras. (BRASIL, 1964)
\end{abstract}

A Lei n. 7.492/1986, que versa sobre crimes contra o sistema financeiro, também fez a equiparação entre as cooperativas de crédito e as instituições financeiras ao dispor que a pessoa jurídica que capte ou administre qualquer tipo de poupança ou recursos de terceiro é equiparado a instituição financeira, como se depreende de seu artigo $1^{\circ}$ :

Art. $1^{\circ}$ - Considera-se instituição financeira, para efeito desta lei, a pessoa jurídica de
direito público ou privado, que tenha como atividade principal ou acessória,
cumulativamente ou não, a captação, intermediação ou aplicação de recursos
financeiros (Vetado) de terceiros, em moeda nacional ou estrangeira, ou a custódia,
emissão, distribuição, negociação, intermediaçãa ou administração de valores
mobiliários.
Parágrafo único. Equipara-se à instituição financeira:
I - a pessoa jurídica que capte ou administre seguros, câmbio, consórcio, capitalização
ou qualquer tipo de poupança, ou recursos de terceiros;
II - a pessoa natural que exerça quaisquer das atividades referidas neste artigo, ainda
que de forma eventual. (BRASIL 1986)

A Constituição Federal de 1988 reforçou a equiparação das cooperativas de crédito às instituições financeiras no capítulo destinado ao Sistema Financeiro Nacional, dispondo o seguinte:

Art. 192 - O sistema financeiro nacional, estruturado de forma a promover o desenvolvimento equilibrado do País e a servir aos interesses da coletividade, em todas as partes que o compõem, abrangendo as cooperativas de crédito, será regulado por leis complementares que disporão, inclusive, sobre a participação do capital estrangeiro nas instituições que o integram. (BRASIL 1988)

A Lei Completar n. 105/2001, que trata da questão pertinente ao sigilo bancário, também dedicou o parágrafo $1^{\mathrm{a}}$, inciso IX, do artigo $1^{\circ}$, para fazer a equiparação entre as instituições financeiras e as cooperativas de crédito:

$\S 1^{\circ}$ - São consideradas instituições financeiras, para os efeitos desta Lei Complementar: (...) 
IX - cooperativas de crédito; (BRASIL 2001)

Sobre a equiparação das cooperativas de créditos às instituições financeiras, Ricardo Negrão (2010, p. 72) assevera: “As cooperativas de crédito são, por natureza, equiparadas às instituições financeiras e submetem-se, como essas, ao regime de intervenção e liquidação extrajudicial, conforme dispõe o art. $1^{\text {a }}$ da Lei 6.024 de 13 de março de 1974".

Logo, por oferecer serviços financeiros similares aos bancos, ainda que restritos quanto a seus destinatários, como depósitos, empréstimos e emissão de talão de cheques, fica claro que as cooperativas de crédito são equiparadas às referidas sociedades, apesar de não se confundirem com as mesmas, pois sua forma societária e seu objeto são completamente distintos.

\subsection{Crise nas cooperativas de crédito: a (in) aplicabilidade do regime falimentar.}

A Lei n. 5.764 de 1971, que define a política nacional do cooperativismo, determina que a dissolução das cooperativas primeiro deverá ser decidida pela Assembleia Geral Extraordinária, que após se manifestar pela dissolução nomeará liquidante para prosseguir com a liquidação da sociedade. O Código Civil de 2002, por sua vez, ao conferir às cooperativas a classificação de sociedade simples, determina que essa modalidade deverá ser dissolvida pela via da liquidação de sociedades.

Entretanto o problema se mostra visível ao tratar das cooperativas de crédito, já que os dois diplomas legais mencionados no parágrafo anterior não mencionam nenhum ramo econômico específico da atividade cooperativa. A Lei n. 6.024/1974, que determina no artigo $1^{\circ}$ a equiparação das cooperativas de crédito às instituições financeiras, permite no seu artigo 34 que estas possam ser submetidas à falência.

Em uma situação de crise nas instituições financeiras, a qual se equipara as cooperativas de crédito, o Banco Central pode decretar intervenção, liquidação extrajudicial ou o Regime de Administração Especial Temporário - RAET - de oficio ou a pedido dos administradores da instituição financeira. Segundo Botrel (2005, p. 60/61):

Constatada a desestabilização de uma instituição, ou verificada a pratica reiterada de infrações às normas bancárias, compete ao Bacen exercer o seu poder-dever de ingerência direta na sociedade bancária, decretando algum regime especial de intervenção, a fim de que a crise que abateu aquela determinada instituição não gere, na medida do possível, efeitos sistêmicos, evitando, desse modo, a contaminação de todo o sistema financeiro. (BOTREL, 2005, p. 60/61)

Pode-se fazer a intervenção, que é de caráter transitório e preventivo, tendo a duração de seis meses e podendo ser prorrogada uma única vez por igual período, quando a instituição financeira apresentar as irregularidades descritas no artigo $2^{\mathrm{a}}$ da Lei n. 6.024/1974. 
A liquidação extrajudicial tem caráter definitivo, extinguindo a empresa quando houver indícios de insolvência irrecuperável, sendo que quase sempre acarreta a cessação da atividade econômica da instituição financeira, prejudicando os empregados, consumidores e a própria sociedade.

Já o RAET foi instituído pelo Decreto-Lei n. 2.321/1997 e também pode ser aplicado às instituições públicas não federal e instituições financeiras privadas. Segundo BOTREL (2005, p. 60) é considerado pela doutrina como o procedimento adequado para se recuperar instituições financeiras, por se tratar de

$$
\begin{aligned}
& \text { uma espécie de intervenção que não interrompe e nem suspende as atividades da } \\
& \text { empresa, sendo seu principal efeito a perda do mandado dos dirigentes da instituição } \\
& \text { e sua substituição por um conselho diretor nomeado pelo Banco Central, com } \\
& \text { amplos poderes de gestão. Sua duração é limitada no tempo e objetiva } \\
& \text { principalmente a adoção de medidas visando à retomada das atividades normais da } \\
& \text { instituição. Quando isso não é possível, pode vir a ser transformada em uma } \\
& \text { intervenção ou liquidação extrajudicial. (BRITO, 2004, p. 11). }
\end{aligned}
$$

A ideia central dessas modalidades de regimes especiais imposta pelo Banco Central não é defender uma instituição financeira e seus credores, mas proteger o mercado e evitar o efeito cascata de sua crise. Sobre a intervenção e a liquidação extrajudicial, BRITO (2004, p. 06) afirma:

\begin{abstract}
A intervenção e a liquidação têm em comum os seguintes aspectos: as instituições financeiras privadas e públicas não federais estão sujeitas à intervenção, à liquidação extrajudicial ou à falência; só poderão ser efetuadas e decretadas pelo Banco Central do Brasil; a intervenção ou liquidação extrajudicial não prejudicam os termos dos arts. 208 e 209 da Lei das Sociedades Anônimas, que norteiam a liquidação pelos órgãos da companhia ou a liquidação judicial. (BRITO 2004, p. 06).
\end{abstract}

Sobre a falência nas instituições financeiras, dispõe o artigo $1^{\text {a }}$ da Lei n. 6.024/1974:

Art. $1^{\circ}$ - As instituições financeiras privadas e as públicas não federais, assim como as cooperativas de crédito, estão sujeitas, nos termos desta Lei, à intervenção ou à liquidação extrajudicial, em ambos os casos efetuada e decretada pelo Banco Central do Brasil, sem prejuízo do disposto nos artigos 137 e 138 do Decreto-lei no 2.627, de 26 de setembro de 1940, ou à falência,, nos termos da legislação vigente. (BRASIL, 1974).

O referido artigo deixa claro que pode aplicar a falência nas instituições financeiras e, consequentemente, nas cooperativas de crédito após o processo de liquidação, liquidação extrajudicial ou RAET pelo Banco Central. Então aqui há um conflito com o inciso II do artigo segundo da Lei n. 11.101/2005, que dispõe o seguinte:

Art. $2^{\circ}$ - Esta Lei não se aplica a:

I - empresa pública e sociedade de economia mista;

II - instituição financeira pública ou privada, cooperativa de crédito, consórcio, entidade de previdência complementar, sociedade operadora de plano de assistência à saúde, sociedade seguradora, sociedade de capitalização e outras entidades legalmente equiparadas às anteriores. (BRASIL, 2005)

No entanto, o artigo 197 da Lei n. 11.101/2005 faz a seguinte ressalva: 
Art. 197 - Enquanto não forem aprovadas as respectivas leis específicas, esta Lei aplica-se subsidiariamente, no que couber, aos regimes previstos no Decreto-Lei $\mathrm{n}^{\circ}$ 73, de 21 de novembro de 1966, na Lei ${ }^{\circ}$ 6.024, de 13 de março de 1974, no DecretoLei no 2.321, de 25 de fevereiro de 1987, e na Lei no 9.514, de 20 de novembro de 1997. (BRASIL, 2005)

O diploma normativo acima mencionado é aplicado para a sociedade em nome coletivo, sociedade comandita simples, sociedade limitada, sociedade anônima e sociedade comandita por ações. Com a sua elaboração pode-se afirmar que o artigo $2^{\mathrm{a}}$ dessa lei revogou em parte a Lei n. 6.024/1974, mas por ser a Lei n. 11.101/2005 considerada uma lei geral da recuperação de empresas e da falência, mantém em vigor as regras jurídicas do diploma legal anterior na qualidade de lei especial. Conforme ensina VERÇOSA (2005, p. 105), "os dois sistemas (o geral e especial) são complementares, prevalecendo este último na confrontação entre ambos".

Ricardo Negrão (2010, p. 68) ensina que há casos de não incidência absoluta da lei, como no caso da empresa pública, sociedade de economia mista e entidades de previdência complementar. Esses casos de não incidência absoluta da Lei n. 11.101/2005 são os dispostos no $\operatorname{artigo} 2^{\mathrm{a}}$, inciso I, da lei supracitada. Já o caso de não incidência relativa da lei ocorre, pois

embora o legislador falimentar tenha afirmado a não aplicação do novo diploma aos casos mencionados, tal assertiva não é absoluta porque a Lei n. 11.101, de 2005 incide enquanto não revogada a extensa legislação que trata dos regimes de liquidação extrajudicial das empresas ali previstas ( NEGRÃO 2010, p. 71).

Continua o autor:

no atual estágio legislativo, as empresas mencionadas no art. $2^{\mathrm{a}}$, II, não estão autorizadas a requerer recuperação em Juízo (judicial ou extrajudicial), porque cabe ao Poder Executivo, em procedimento de intervenção administrativo, buscar o saneamento de sua atividade, autorizando o liquidante a requerer falência, se necessário, nos casos previstos em lei. Entretanto, uma vez decretada a quebra, incidem as regras da lei n 11.101, de 2005 (NEGRÃO 2010, p. 71).

Em se tratando das instituições financeiras, ao se fazer a recepção da legislação especial através da lei de recuperação judicial e falências, tem se as seguintes alternativas, segundo VERÇOSA (2005, p. 107/108):

a) O Banco Central do Brasil tem a prerrogativa de adotar qualquer dos regimes interventivos ao seu dispor;

b) No curso de um deles, caso apurada uma das situações legais específicas, o Banco Central do Brasil autorizará o interventor, o liquidante extrajudicial ou o Conselho Diretor do RAET a requerer a decretação da falência a juiz competente;

c) Diante da inércia do Banco Central em relação a uma de tais entidades insolventes ou inadimplentes, qualquer credor poderá requerer a sua falência; e

d) Não podem tais empresas recorrer aos sistemas de recuperação da nova lei porque seu regramento específico já prevê uma sistemática própria, a cargo da Autoridade Monetária. (VERÇOSA, 2005, p. 107/108).

O caso das cooperativas se torna confuso, pois o legislador do Código Civil de 2002 deu a elas natureza jurídica de sociedade simples no art. 982 e o art. 1.096 dispõe que se aplica as regras das sociedades simples às cooperativas no que a legislação especifica for omissa. 
Nesse ponto retoma-se a questão da natureza jurídica já discutida anteriormente. Se a cooperativa (e todos seus ramos, incluindo a de crédito) são sociedades simples, não se aplica às mesmas a Lei n. 11.101/2005. Mas a cooperativa de crédito, que é equiparada tanto pela Constituição Federal de 1988, em seu art. 192, quanto pelas Leis n. 4.595/1964, no art. 18, $\S 1^{\circ}$, e 7.492/1986, em seu art. 1 a , com as instituições financeiras; então a elas é aplicado o que a lei especial dispõe sobre as mencionadas sociedades.

Assim, deve-se observar o art. $1^{\circ}$ da Lei n. 6.024/1974 e compará-lo com os artigos $2^{\mathrm{a}}$, inciso II, e 197 da Lei n. 11.101/2005. Isto porque, como o inciso II do art. $2^{\mathrm{a}}$ da Lei das Falências não é de aplicação absoluta e observando a ressalva de seu art. 197, pode ser aplicado o regime falimentar para as cooperativas de crédito. Ressalta-se que apenas a falência será aplicada nas instituições financeiras e cooperativas de crédito, pois conforme ensina VERÇOSA (2005, p. 106):

A lei 11101, de 2005 não se aplicará, evidentemente, às instituições financeiras no que tange aos dois modelos de recuperação nela previsto, continuando o Banco Central do Brasil a manter em suas mãos os três institutos da legislação especial. (VERÇOSA 2005, p. 106)

Sobre a aplicação da falência nas cooperativas de crédito, o citado autor (2005, p. 110) mostra que:

Tendo em conta as cooperativas de crédito e sua condição de instituição financeira, como tais elas expressamente estão sujeitas à Lei 6.024/74 e ao DEC. - Lei 2.321/87, ou seja, à intervenção, à liquidação extrajudicial e ao regime de administração especial temporário. Assim sendo, também estariam sujeitas à falência quando seu requerimento for autorizado pelo Banco Central do Brasil nos casos de passivo superior a 50\% do ativo. (VERÇOSA, 2005, p. 110).

Em 2009 foi publicado o acórdão com revisão n. 507. 700- 4/ 6 - 00 no Tribunal de Justiça de São Paulo - TJSP, no qual o relator Desembargador José Roberto Lino Machado entendeu aplicável o regime falimentar, com a aplicação da Lei n. 11.101/2005, para uma cooperativa de crédito. Consta na ementa do referido acórdão:

Cooperativa de Crédito - Liquidação extrajudicial - Requerimento de autofalência Admissibilidade. Não se decreta nulidade de sentença que, embora sucinta, esteja suficientemente fundamentada - Impugnação ao valor da causa há de ser oposta incidentalmente ao pedido principal - Possível deferimento da justiça gratuita, ou, pelo menos, o diferimento do pagamento das custas, a favor da liquidanda quando postula sua autofalência - Cooperativas de crédito sujeitam-se à decretacão de falência. Apelação provida para decretar a falência da liquidanda. Conhecimento, em parte, da apelação do quotista e, na parte conhecida, desprovida. (SÃO PAULO, 2009) (destaque nosso)

Em seu voto o relator argumenta que a Lei n. 6.024/1974 autoriza a liquidação extrajudicial, intervenção e falência para as cooperativas de crédito e instituições financeiras. Sustenta ainda que a Lei n. 11.101/2005 acolheu em parte o mencionado diploma legal, de forma subsidiária, "enquanto não forem aprovadas as leis específicas - art. 197”. Afirma ainda que o pedido de falência deve ser feito pelo liquidante ou interventor nomeado pelo Banco Central e que este deve autorizar sua procedência. Na fundamentação destaca que em caso de crise nas cooperativas de crédito, estas deverão obedecer as normas especificas, conforme 
disciplina o art. 78 da Lei n. 5.764/1971, que dispõe: "A liquidação das cooperativas de crédito e da seção de crédito das cooperativas agrícolas mistas reger-se-á pelas normas próprias legais e regulamentares".

Apesar de o TJSP ter decretado falência para uma cooperativa de crédito, o uso da Lei

n. 11.101/2005 na visão do próprio Tribunal é apenas quando o liquidante ou interventor pede sua falência para o Banco Central. O professor Haroldo Malheiros Dulcrerc Verçosa defende que se decretada a intervenção ou liquidação judicial o credor não pode mais pedir a falência da cooperativa de crédito ou instituição financeira, apenas o liquidante ou interventor; na hipótese do Banco Central permanecer omisso sobre a crise na cooperativa de crédito ou qualquer outra instituição financeira, pode o credor pedir sua falência, conforme estabelece o artigo 97, inciso IV.

Pesquisando sobre o tema na jurisprudência do Superior Tribunal de Justiça - STJ, constatou-se que de 298 acórdãos ${ }^{10}$ apenas uma decisão trata sobre a aplicação subsidiária da falência às cooperativas de crédito. Nos demais ramos a posição da Corte é no sentido de se afastar a adoção da Lei de Falências, deixando expresso que por ser sociedade simples as cooperativas se submetem à liquidação de sociedades prevista no Livro das Empresas no Código Civil.

O acórdão em questão deixa expresso o entendimento do STJ quanto a aplicação subsidiária da falência às cooperativas de crédito - o Recurso Especial n. 1274623 / MG de relatoria da Ministra Nancy Andrighi, publicado em 18/06/2014.

DIREITO CIVIL E PROCESSUAL CIVIL. RECURSO ESPECIAL. AÇÃO RESCISÓRIA. LIQUIDAÇÃO EXTRAJUDICIAL. COOPERATIVA DE CRÉDITO. AÇÃO INDIVIDUAL. COMPENSAÇÃO DE DÉBITO E RESTITUIÇÃO DE VALORES. SUBMISSÃ̃ À LIQUIDAÇÃO EXTRAJUDICIAL. ARTS. ANALISADOS: $1^{\circ}, 3^{\circ}, 15,18$ E 34 DA LEI N ${ }^{\circ} 6.024 / 76$; 73, 76, 78 e 116 da LEI No 5.764/71; E 46 DO DECRETO-LEI No 7.661/45. 1. Ação rescisória ajuizada em 17/9/2008. Recurso especial concluso

ao Gabinete em 27/9/2011. 2. Ação rescisória que discute a existência de violação literal de dispositivo de lei em demanda originária de compensação de débito e restituição de valores proposta após o deferimento de liquidação extrajudicial de cooperativa de crédito. 3 . A liquidação extrajudicial de cooperativa de crédito deve atender os dispositivos da Lei 6.024/76 e da Lei de Falência subsidiariamente porquanto têm natureza jurídica de instituição financeira não-bancária. 4. Configurada a violação literal de dispositivos legais, deve-se proferir de imediato novo julgamento, mormente quando o acórdão cassado debatia questão eminentemente de direito. 5. Deferida a liquidação extrajudicial de cooperativa de crédito pelo Banco Central do Brasil, a satisfação dos direitos de crédito contra a cooperativa liquidanda deverá ser realizada coletivamente, por rateio e respeitada a ordem de preferências legais. 6 . A compensação de débitos e créditos embor admitida deverá ser realizada no bojo do procedimento de habilitação, com os instrumentos de impugnação previstos na Lei $\mathrm{n}^{\circ} 6.024 / 76$, e não em ação individual.

7. Recurso especial provido para cassar o acórdão rescindendo e, em novo julgamento da demanda de fundo, negar provimento à apelação. (Grifo nosso) (BRASIL, 2014).

O voto da Ministra Nancy Andrighi está de acordo com a tese levantada pelo presente trabalho. A Lei n. 11.101 de 2005 pode ser aplicada às cooperativas de crédito após a liquidação

${ }^{10}$ Pesquisa realizada em agosto de 2019. 
pelo Banco Central, conforme previsto pelo artigo 34 da Lei n. 6.024/1974. Não deve ser adotada, todavia, para as demais modalidades de cooperativa, aplicando-se o regramento das sociedades simples, como já contextualizado.

\section{Conclusão}

O ramo do cooperativismo de crédito ocupa a terceira posição no ranking do cooperativismo. Possuía em 2012, segundo dados da OCB, 5.487.098 associados, 38.132 empregados e 1.042 cooperativas e esse número passou para, segundo o Banco Central em 2013, 6.393 .825 associados, 41.152 empregados e 1.154 cooperativas, mostrando que a cada ano o ramo crédito cresce amplamente.

Diante desses números, resta claro que as cooperativas são muito importantes para a economia brasileira movimentando uma quantia considerável de dinheiro. Caso ocorra uma crise em uma cooperativa de crédito, deve-se evitar que o efeito dominó característico no mercado financeiro não desperte a desconfiança da sociedade.

A Lei n. 6.024/1974 prevê a aplicação para as instituições financeiras e as cooperativas de crédito do regime jurídico intitulado da intervenção e da liquidação extrajudicial, decretados pelo Banco Central do Brasil. Posteriormente o Decreto-Lei n. 2. 321/1987 criou o RAET Regime de Administração Especial Temporário, também adotado no mesmo formato para as entidades em destaque.

Porém, a dúvida surgiu com o advento da Lei n. 11.101/2005, a Lei da Recuperação Judicial, Extrajudicial e Falências, que no artigo $2^{\text {a }}$, inciso II, exclui de sua aplicação as instituições financeiras e as cooperativas de crédito, fazendo ressalva no artigo 197 no tocante à possibilidade de sua adoção através de lei especial.

Tendo em vista que a denominada Lei da Falência é considerada norma geral sobre a matéria, sendo que a Lei n. 6.024/1974 traz disciplina especial, resta aplicável às cooperativas de crédito o diploma legal geral, sendo competência do Banco Central seu encaminhamento.

Conclui-se que o regime falimentar pode ser aplicado às cooperativas de crédito por serem equiparadas às instituições financeiras, sendo que qualquer credor poderá pedir em juízo a decretação de sua falência com fulcro no artigo 97, inciso IV, da Lei n. 11.101/2005, mas apenas em caso de omissão e inércia do Banco Central frente à situação de crise econômica por parte da mesma.

\section{Referências bibliográficas.}


BITTENCOURT, Gilson Alceu; Central Única dos Trabalhadores (Brasil); Confederação Nacional dos Trabalhadores na Agricultura (Brasil). Cooperativas de crédito. São Paulo: CUT: CONTAG, 1999.

BRASIL. Lei n ${ }^{\circ}$ 5764, de 16 de dezembro de 1971. Define a Política Nacional de Cooperativismo, institui o regime jurídico das sociedades cooperativas, e dá outras providências. Disponível em: < http://www.planalto.gov.br/ccivil_03/leis/15764.htm>. Acesso em: 01 set. 2018.

BRASIL. Lei n ${ }^{\circ}$ 6024, de 13 de março de 1974. Dispõe sobre a intervenção e a liquidação extrajudicial de instituições financeiras, e dá outras providências. Disponível em: <http://www.planalto.gov.br/ccivil_03/leis/L6024.htm>. Acesso em: 01 set. 2018.

BRASIL. Lei 7492, de 16 de junho de 1986. Define os crimes contra o sistema financeiro nacional, e dá outras providências. Disponível em: <

http://www.planalto.gov.br/ccivil_03/Leis/17492.htm>. Acesso em: 01 set. 2018.

BRASIL. Constituição (1988) Constituição da República Federativa do Brasil. Brasília: Senado, 1988.

BRASIL. Código Civil. Disponível em:< http://www.planalto.gov.br/ccivil_03/leis/2002/110406.htm>. Acesso em 01 set. 2018.

BRASIL. Lei $\mathrm{n}^{\circ} 11.105$, de 09 de fevereiro de 2005. Regula a recuperação judicial, a extrajudicial e a falência do empresário e da sociedade empresária. Disponível em: <http://www.planalto.gov.br/ccivil_03/_ato2004-2006/2005/lei/111101.htm>. Acesso em 01 set. 2018.

BRASIL. STJ. Recurso Especial n. 1274623/MG. Recorrente: Credibel Cooperativa de Crédito rural de Belo Horizonte Ltda. Recorrido: Paulo de Magalhães Goes. Relator: Min. Nancy Andrighi. Data do julgamento 10/06/2014. T3- Terceira turma. Data da Publicação DJ $18 / 06 / 2014$.

BRITO, Cristiano Gomes. O Regime de administração especial temporária - RAET. Revista de Direito Mercantil, Industrial, Econômico e Financeiro, n. 133. São Paulo: Maheiros Editores, jan./mar. 2004, p. 155-173.

BOTREL, Sergio. Insolvência Bancaria: responsabilidade do Banco Central do Brasil; liquidação extrajudicial, intervenção extrajudicial, Regime de Administração Especial Temporário (RAET). Belo Horizonte: Del Rey, FCH FUMEC, 2005

BULGARELLI, Waldírio. As sociedades cooperativas e a sua disciplina jurídica. 2.ed. Rio de Janeiro: Renovar, 2000.

BULGARELLI, Waldírio. Elaboração do direito cooperativo: um ensaio de autonomia. 1. ed. São Paulo, Atlas, 1967.

CARNERO, Palmyos Paixão. Cooperativismo: o principio cooperativo a força existencial do trabalho. Belo Horizonte, FUNDEC, 1981. 
LEITE, Jacqueline Rosadine de Freitas. Os bancos cooperativos no sistema financeiro nacional. In. . In. LEITE, Jaqueline Rosadine de Freiras; SENRA, Ricardo Belizio de Faria. Aspectos jurídicos das cooperativas de crédito. Belo Horizonte: Mandamentos, 2005.

NEGRÃO, Ricardo. Aspectos objetivos da lei de recuperação de empresas e de falências: lei n. 11.101, de 9 de fevereiro de 2005. 4. ed. São Paulo: Saraiva, 2010.

NEGRÃO, Ricardo. Manual de direito comercial e de empresa: volume 1 : teoria geral da empresa e direito societário. 7. ed. rev. e atual. São Paulo: Saraiva, 2010

NEGRÃO, Ricardo. Manual de direito comercial e de empresa: volume 3 : recuperação de empresas e falências. 5. ed. São Paulo: Saraiva, 2010. 802 p. (Coleção Manual de Direito Comercial e de Empresa).

ORGANIZAÇÃO DAS COOPERATIVAS DO BRASIL. História: Nascimento de uma grande ideia. Disponível em: < http://www.ocb.org.br/site/cooperativismo/historia.asp>. Acesso em: 02 ago. 2019.

ORGANIZAÇÃO DAS COOPERATIVAS DO BRASIL. Evolução no Brasil. Movimento livre da influencia do Estado. Disponível em:

<http://www.ocb.org.br/site/cooperativismo/historia.asp>. Acesso em: 02 ago. 2019.

ORGANIZAÇÂO DAS COOPERATIVAS DO BRASIL. Número das cooperativas de crédito no Brasil. Disponível em: 〈http://www.ocb.org.br/site/ramos/credito_numeros.asp $>$. Acesso em: 02 ago. 2019.

ORGANIZAÇÂO DAS COOPERATIVAS DO BRASIL. Evolução do número de cooperativas. Disponível em: <

http://www.brasilcooperativo.coop.br/GERENCIADOR/ba/arquivos/140411_apresentacaoins titucional2010_1.pdf>. Acesso em: 02 ago. 2019.

ORGANIZAÇÃ̃ DAS COOPERATIVAS DO ESTADO DE MINAS GERAIS. Anuário de informações econômicas e sociais do cooperativismo mineiro. Disponível em:

<http://www.minasgerais.coop.br/Repositorio/Publicacoes/anuario_2013/index.html\#/10/>. Acesso em: 02. ago. 2019.

PINHEIRO, Marcos Antonio Henriques. Cooperativas de credito: história da evolução normativa no Brasil. 6. ed. Brasília: BCB, 2008.

PORTAL DO COOPERATIVISMO FINANCEIRO. Países com maior expressão no cooperativismo de crédito. Disponível em:

$<<$ http://cooperativismodecredito.coop.br/cooperativismo-de-credito-no-mundo/a-expressaomundial/>. Acesso em: 02 ago. 2019.

PORTAL DO COOPERATIVISMO FINANCEIRO. Dados estatísticos do cooperativismo mundial segundo o WOCCU. Disponível em:

$<$ http://cooperativismodecredito.coop.br/cooperativismo-de-credito-no-mundo/a-expressaomundial/>. Acesso em: 02 ago. 2019.

PORTAL DO COOPERATIVISMO FINANCEIRO. A expressão mundial. Disponível em: $<$ http://cooperativismodecredito.coop.br/cooperativismo-de-credito-no-mundo/a-expressaomundial/>. Acesso em: 02. ago. 2019. 
PORTAL DO COOPERATIVISMO FINANCEIRO. Os pioneiros de Rochdale. Disponível em: http://cooperativismodecredito.coop.br/historia-do-cooperativismo/os-pioneiros-derochdale/>. Acesso em: 02. ago. 2019.

PORTAL DO COOPERATIVISMO FINANCEIRO. Sistema Raiffeisen. Disponível em: <http://cooperativismodecredito.coop.br/historia-do-cooperativismo/sistema-raiffeisen/> acesso em: 02. ago. 2019.

PORTAL DO COOPERATIVISMO FINANCEIRO. O movimento Desjardins. Disponível em: <http://cooperativismodecredito.coop.br/historia-do-cooperativismo/o-movimentodesjardins/>. Acesso em: 02. ago. 2019.

REIS JÚNIOR, Nilson. Aspectos societários das cooperativas. Belo Horizonte:

Mandamentos, 2006.

SÃO PAULO. Tribunal de Justiça. Apelação com Revisão n ${ }^{\circ}$ 507.700.4/6-00. Cooperativa de Crédito - Liquidação extrajudicial - Requerimento de autofalência - Admissibilidade.

Apelantes: Cooperativa de Crédito Popular de Olímpia (em liquidação extrajudicial); Milton Gigliotti Apelados: os mesmos. Relator José Roberto Lino Machado, São Paulo, 28 de jul. 2009. DJ, São Paulo, 2009.

SENRA, Ricardo Belízio de Faria. Cooperativa de crédito e banco: o malogro da analogia e a preponderância da assimetria. In. LEITE, Jaqueline Rosadine de Freiras; SENRA, Ricardo Belizio de Faria. Aspectos jurídicos das cooperativas de crédito. Belo Horizonte:

Mandamentos, 2005.

VERÇOSA, Haroldo Malheiros Duclerc. Curso de direito comercial: volume 2: teoria geral das sociedades - as sociedades em espécie do Código Civil. 2. ed., rev. e atual. São Paulo: Malheiros, 2010.

VERÇOSA, Haroldo Malheiros Duclerc. Das pessoas sujeitas e não sujeitas aos regimes de recuperação de empresas e ao da falência. In PAIVA, Luiz Fernando Valente. Direito Falimentar e a nova Lei de Falências e Recuperação de Empresas. São Paulo: Quartier Latin, 2005, pp. 61-118. 